\title{
O leve ajuste do método: reconstrução normativa e experimentalismo socialista na Teoria Crítica de Axel Honneth*
}

\author{
The Slight Adjust of Method: Normative Reconstruction and Socialist \\ Experimentalism in Axel Honneth's Critical Theory
}

\author{
Luiz Repa \\ luizrepa@uol.com.br \\ (Universidade de São Paulo, São Paulo, Brasil)
}

\begin{abstract}
Resumo: 0 artigo propõe uma linha de interpretação sobre o nexo entre método e política no pensamento de Axel Honneth, especialmente no que diz respeito à sua proposta de renovação da ideia de socialismo. Na primeira seção do artigo, busca-se mostrar que Honneth se vale da noção habermasiana de reconstrução racional para recriar nessa tradição uma unidade entre fundamentação normativa e análise social. Desse modo, Honneth pode reconfigurar a história da Teoria Crítica como uma sucessão de modelos reconstrutivos. No passo seguinte, procura-se reconstituir os primeiros usos honnethianos da noção de reconstrução até chegar às formulações mais sistemáticas encontradas em $\mathrm{O}$ direito da liberdade. $\mathrm{Na}$ última seção, examina-se o experimentalismo socialista proposto por Honneth acentuando o deslocamento do sentido do método em seu pensamento. De modo geral, o artigo defende que o projeto socialista honnethiano comporta uma inovação política no mínimo instigante, a qual, por outro lado, paga o preço de um grau de abstração maior no nível do método.
\end{abstract}

Palavras-chave: Axel Honneth; reconstrução; socialismo; Teoria Crítica; método.

\begin{abstract}
The article proposes a line of interpretation on the connection between method and politics in Axel Honneth's thought, particularly concerning his proposal of renewing the idea of socialism. In the first section, it seeks to show that Honneth makes use of the Habermasian notion of rational reconstruction to recreate a unity of normative foundation and social analysis within this tradition. In doing so, Honneth can reshape the history of Critical Theory as a succession of reconstructive models. In the second section, I try to reconstitute Honneth's notion of reconstruction from its first uses to the most systematic formulations found in Freedom's Right. In the last section, I address the socialist experimentalism proposed by Honneth highlighting the displacement of the meaning of method in his theory. In general, the article argues that Honneth's socialist project encompasses a thought-provoking political innovation which, on the other hand, must pay the price of a higher degree of abstraction in the methodological level.
\end{abstract}

Keywords: Axel Honneth; reconstruction, socialism; Critical Theory; method.

DOI: http://dx.doi.org/10.11606/issn.2318-9800.v25i3p95-112

A relação entre método e política sempre foi um tema caro à Teoria Crítica. Ao estabelecer o interesse pela emancipação como o traço distintivo da Teoria Crítica em contraposição à teoria tradicional, Max Horkheimer defendeu que os métodos

\footnotetext{
* O autor agradece aos dois pareceristas do presente ensaio, cujas sugestões e críticas rigorosas não puderam ser inteiramente satisfeitas na sua versão final. Elas, no entanto, acompanharão a continuidade da reflexão sobre o socialismo em Honneth.
} 
de conhecimento da realidade, humana e natural, não são politicamente neutros (Horkheimer, 1988, p. 195 ss.). Delineando as condições por meio da qual a teoria pode satisfazer aquele interesse, ele pensa o comportamento crítico como um conhecimento da realidade a partir das possibilidades de transformação capaz de emancipar a sociedade de coerções econômica, cultural e psiquicamente enraizadas (idem, p. 180 ss.). Ao mesmo tempo, o nexo com a práxis não retira da Teoria Crítica sua objetividade. Pelo contrário, a ilusão de autonomia científica, baseada nas exigências de neutralidade axiológica e o consequente afastamento de toda normatividade, é o que faz o ideal do conhecimento objetivo sucumbir a interesses particulares, não científicos (idem, pp. 168, 171). Por sua vez, o interesse pela emancipação impele para o autoconhecimento da teoria e de sua dependência em relação à práxis social geral.

Dessa maneira, a Teoria Crítica tem sido marcada por uma reflexão de método que jamais se reduz à simples apreensão objetiva, neutra, da realidade. As autoras e os autores que se pretendem filiar a essa corrente, reinterpretando suas características, podem discordar quanto ao feitio do método e ao sentido da emancipação, mas não quanto à necessária junção entre as duas preocupações.

Por outro lado, essa junção não é de modo algum simples. O próprio Horkheimer é um exemplo de quão complexa se tornou a relação entre teoria e práxis, conhecimento e interesse, método e política (cf. Nobre, 2015). Ao diagnosticar a integração do proletariado ao sistema capitalista, a sua adesão a movimentos fascistas, as mudanças na estrutura e produção de ideologias, o método perde sua cristalização lógica autoevidente, e o sentido da emancipação se torna mais abstrato (cf. Horkheimer, 1988, p. 214 ss.; Dubiel, 1978).

Essa constelação pode se tornar um pouco mais apreensível quando colocamos em questão o que significa "socialismo" para a Teoria Crítica. Até o começo do século XX não se tinha dúvida, entre marxistas de várias vertentes, a respeito da equação direta entre emancipação e socialismo. Emancipada era, sem dúvida, uma sociedade socialista. É digno de nota que tal vínculo não transpareça sistematicamente nas compreensões preponderantes da Teoria Crítica. Até recentemente, apenas Marcuse (e isso somente a partir do final dos 1960) ${ }^{1}$ e Habermas (após a queda do muro de Berlin $)^{2}$ procuraram redefinir um pouco mais sistematicamente o significado do

\footnotetext{
1 A reinterpretação marcuseana é fortemente marcada pela atenção dada aos novos movimentos sociais dos anos 1960 , ao mesmo tempo em que se preserva em grande medida a crítica anterior à racionalidade técnica. "Essa alternativa não é tanto uma estrada diferente para o socialismo quanto uma emergência de metas e valores diferentes, diferentes aspirações nos homens e nas mulheres que resistem e negam o poder explorador massivo do capitalismo corporativo, mesmo em suas realizações mais confortáveis e liberais. A Grande Recusa toma uma variedade de formas." (Marcuse, 1969, p. vii). Sobre a percepção dos movimentos sociais e o paradigma da revolução, cf. Terra, R. (2011). "Os limites do paradigma da revolução: ciência, técnica e movimentos sociais". In: Nobre, M. (org.) Curso livre de Teoria Crítica. Campinas: Papirus.

2 Habermas reinterpreta o sentido do socialismo à luz das condições exigentes de deliberação
} 
O leve ajuste do método: reconstrução normativa e experimentalismo socialista ...

socialismo. ${ }^{3}$

Já por isso o opúsculo de Honneth sobre a ideia de socialismo, publicado em 2015 e ampliado em 2017, representa algo de ímpar na história da Teoria Crítica. Em certo sentido, ele quebra o silêncio quase completo da Teoria Crítica sobre a necessidade de uma renovação das ideias socialistas de forma mais integral. No entanto, também isso é inesperado da parte dele. Antes de A ideia do socialismo, esse silêncio vinha do próprio Honneth, já que suas críticas ao capitalismo não eram até então seguidas de uma justificativa mais aguda de caminhos mais radicais. Luta por reconhecimento pretendia ser a base de uma teoria crítica dos conflitos sociais que ao fim e ao cabo deixa em suspenso a compatibilidade entre a lógica normativa das lutas por reconhecimento e as condições do capitalismo contemporâneo, reservando a questão para o "futuro das lutas sociais" (Honneth, 2003, p. 280). Ao longo da primeira década deste século, os vários ensaios dedicados aos fenômenos patológicos (sofrimento de indeterminação, reificação, invisibilidade social, paradoxos da individualização e ideologias de reconhecimento), bem como à crise neoliberal no mundo do trabalho, geralmente apresentavam uma estratégia clara de aprofundar as estruturas de reconhecimento e implantar uma crítica imanente e reconstrutiva com base nelas, sem apelar a uma via política mais definida. Honneth mudou essa linha de pensamento somente quando confrontado com uma série de críticas contra o aspecto supostamente moderado ou mesmo conservador das reconstruções normativas propostas em 0 direito da liberdade (Schaub, 2015; Jütten 2015). Só então ele assume que certas revoluções institucionais poderiam acompanhar as reconstruções normativas:

Foi apenas na discussão do meu livro que se seguiu à sua publicação que ficou claro para mim o quão errado (à luz de minhas próprias considerações) era não ter permitido em minha reconstrução normativa uma maior maleabilidade institucional

democrática: “Quando se concebe o 'socialismo' como sumário das condições necessárias para formas de vida emancipadas, sobre as quais os próprios participantes precisam se entender primeiramente, reconhece-se que a auto-organização democrática de uma comunidade direito forma o cerne normativo também desse projeto" (Habermas, 1992, p. 12); cf. igualmente Habermas, 1990 e 2013. Embora a concepção honnethiana de socialismo democrático se inspire na habermasiana, há diferenças relevantes quanto à fundamentação e ao alcance delas, as quais não posso discutir aqui.

3 Isso não implica dizer, porém, que não se encontrem nos diversos autores da Teoria Crítica suposições de fundo sobre a sociedade socialista. Nos escritos de Friedrich Pollock dos anos 1930, por exemplo, o socialismo aparece como uma possibilidade ligada ao desenvolvimento do capitalismo, cada vez mais subordinado ao planejamento político-estatal, de modo que a posição social das classes dirigentes seria decisiva. Nesse caso, a sociedade socialista se deixa definir em primeira linha como economia planificada em uma estrutura social sem classes. A classe em posse do poder estatal definiria se está em jogo uma planificação socialista ou capitalista (cf. Pollock, 2019, p. 45). À contraluz, também seria possível traçar algumas linhas da concepção de socialismo em Franz Neumann, partindo da relação entre o direito e a democracia, de um lado, e, de outro, o capitalismo monopolista, tanto em Weimar como na sequência totalitária. Igualmente poderíamos perseguir a ideia de "socialismo" como paradigma de justiça distributiva em Nancy Fraser. Porém, salvo engano, falta a essas e outras abordagens da Teoria Crítica, por diferentes motivos, incluindo sobretudo os históricos, uma determinação mais sistemática da ideia de socialismo. 
na realização gradual das normas específicas às esferas. Se eu tivesse feito isso, teria deixado em aberto a possibilidade de lidar com casos de "revolução institucional". Ela consiste na possibilidade de que a norma subjacente a uma determinada esfera de ação só possa ser realizada de maneira mais apropriada e abrangente por meio de uma mudança fundamental da instituição que havia sido servida anteriormente para realizá-la (Honneth, 2015, p. 208).

De acordo com essa formulação, $A$ ideia do socialismo dependeria apenas de um "leve ajuste [kleine Drehung] na perspectiva adotada em $O$ direito da liberdade, a fim de abri-la a uma ordem social constituída de maneira completamente diferente" (2017, p. 12 [trad., p. viii]). Essa nova ordem é o socialismo democrático.

Antes de abordar o que pode significar um tal “ajuste", é indispensável compreender o quão ímpar é também essa compreensão do socialismo em termos normativos, já que o eixo da atualização da ideia do socialismo se encontraria menos na noção de igualdade material do que na categoria de liberdade social. O socialismo honnethiano não é propriamente uma resposta às questões de justiça distributiva ou de organização coletiva da produção, um modo de produção. Ele tem a ver antes de tudo com uma comunidade de solidariedade que seria a condição e o caminho necessário para o exercício da "verdadeira liberdade”, ou seja, "a liberdade social”, que

significa participar na práxis social de uma comunidade em que os membros demonstram tanto envolvimento [Anteilnahme] mútuo que eles propiciam reciprocamente a realização de suas necessidades justificadas por mor do respectivo outro (...). Aquilo a que se refere a liberdade - a efetivação desimpedida o máximo possível dos próprios propósitos ou fins - não pode ser realizado por uma pessoa em particular, mas apenas por uma coletividade constituída de maneira correspondente, sem que esta deva ser considerada por isso como uma entidade de nível superior em relação às partes (2017, p. 47 [trad., p. 24]).

Portanto, socialismo designa primeiramente tal comunidade de solidariedade que garante a liberdade na medida em que elabora as relações de reconhecimento recíproco que permitem a cada um ver no outro a condição das realizações de seu próprio fim, de um modo não instrumental. A livre realização dos objetivos de cada um é intimamente associada ao interesse na autorrealização da parceira e parceiro de interação. Não se trata, porém, apenas de chamar a atenção para a estrutura intersubjetiva da liberdade. Ver o outro como condição da própria liberdade, não como um meio para a liberdade, requer um processo de formação que só pode se constituir em práticas institucionalizadas, não necessariamente juridificadas, de reconhecimento recíproco (Honneth, 2011, p. 86 ss. [trad., p. 44 ss.]).

De acordo com Honneth, essas práticas se consolidam em três sistemas de ação distintos nas condições da sociedade moderna marcada pela diferenciação funcional: o âmbito das relações pessoais, das atividades econômicas propriamente 
O leve ajuste do método: reconstrução normativa e experimentalismo socialista ...

ditas e a esfera pública política. Cada uma dessas esferas representa uma dimensão própria da liberdade social. Como o socialismo seria a efetividade da liberdade social em práticas institucionais interconectadas, Honneth pode então considerá-lo uma "forma de vida democrática":

Democracia não significa aqui apenas poder participar em pé de igualdade e sem coerções nos procedimentos de formação política da vontade; entendida como uma forma de vida inteira, ela se refere antes à possibilidade de fazer, na estação central da mediação de indivíduo e sociedade, a experiência de uma participação igualitária, na qual se reflete a cada vez a estrutura geral da participação democrática na particularidade funcional de uma única esfera (2017, p. 144-145 [trad., p. 92]).

Em síntese, o socialismo consiste em uma forma de vida democrática que representa a efetivação da liberdade social em cada âmbito fundamental da sociedade: as relações de intimidade, de trabalho e de formação da vontade política. Tal abordagem possui consideráveis ganhos teóricos e políticos. Uma vez que o foco não se restringe ao âmbito econômico porque este não é a única dimensão da liberdade (embora ele seja ainda decisivo, como veremos adiante), Honneth pode tornar o projeto socialista sensível e aberto às novas formas de conflito social: "agora, não há mais simplesmente apenas a oposição de 'trabalhadores' e 'capitalistas', mas a par disso, e igualmente com relevância e dinâmica conflitual, também entre os parceiros de amor, os membros familiares, as cidadãs e cidadãos políticos” (2017, p. 149 [trad., p. 95]).

Além disso, dado que o conceito de liberdade social permite superar a divisão tradicional entre autonomia pública e privada, ou privacidade e vida pública, é possível uma espécie de “democratização da intimidade" (Silva, 2013, p. 214). É que a teoria da liberdade de Honneth limita a autonomia privada às concepções legais e morais, enquanto a esfera pessoal deve ter uma constituição intersubjetiva positiva e estar aberta ao questionamento democrático para que possa lidar com os conflitos daí decorrentes. Certamente, já em $O$ direito da liberdade, pode-se observar uma democratização na esfera íntima, por exemplo, quando Honneth aborda os desenvolvimentos na "forma institucional do amor", na qual o "novo padrão de relacionamento seria totalmente 'democratizado' no sentido de que podia formar uma possibilidade disponibilizada igualmente não apenas para formação de casais heterossexuais, mas também de casais homossexuais” (2011, p. 252 [trad., p. 142]). Agora, essa tendência parece ser mais intensificada, na medida em que a democracia deve aqui ser uma forma de vida de acordo com a ideia do socialismo, e isso significa: através de uma elaboração viva e livre das estruturas normativas de reconhecimento mútuo. ${ }^{4}$ Trata-se, portanto, de avanços significativos para os esforços de retomar as

4 Cabe dizer, por outro lado, que tais potencialidades conceituais têm de conviver com uma compreensão organicista de forma de vida que acaba estorvando-as. Deixo para outro lugar a discussão sobre esse ponto. 
ideias socialistas para além do marxismo convencional.

Contudo, a formulação acima - um leve ajuste metodológico para obter uma ordem social completamente diferente - é escancaradamente paradoxal e faz lançar a questão de como o método da reconstrução se relaciona com tal projeto socialista. Para abordá-la, vou retomar os usos que a noção de reconstrução recebe em Honneth, tendo em vista em primeiro lugar o seu papel de unificar a teoria crítica após as mudanças de método propostas por Habermas, e, em seguida, as formulações mais sistemáticas alcançadas em $O$ direito da liberdade. Na parte final, volto-me à relação entre o método da reconstrução normativa e o experimentalismo socialista com que Honneth busca se afastar da teoria marxista tradicional do desenvolvimento do socialismo. Embora o "ajuste" socialista tenha uma produtividade política considerável, ele corre o sério risco de tornar mais abstrata a reconstrução normativa enquanto tal, principalmente em comparação com a obra de 2011, cuja riqueza histórica tinha a ver diretamente com o envolvimento dos desdobramentos institucionais em cada esfera da liberdade social. Enquanto a reconstrução normativa tem de lidar com possibilidades objetivas examináveis apenas em contextos institucionais particulares, o experimentalismo socialista pressupõe uma distância entre as estruturas da liberdade social e estes contextos.

Embora Honneth reporte sempre o conceito de reconstrução normativa aos procedimentos metodológicos de Hegel na Filosofia do Direito, não é possível separálo de sua principal fonte: as noções habermasianas de "reconstrução racional", "ciência reconstrutiva" ou "procedimento reconstrutivo" (Habermas, 1976/1984, 2016, 1989). Não cabe aqui reconstituir todos os desenvolvimentos habermasianos, sempre muito intricados (cf. Repa, Nobre, 2012). Limito-me apenas a delinear um certo percurso e algumas ideias fundamentais que estão na base dos desdobramentos da Teoria Crítica no século XX.

O conceito de reconstrução emerge em Habermas no momento em que ele desiste de uma renovação psicanalítica da crítica à ideologia, na medida em que passa considerar esse tipo de crítica como demasiadamente dependente da normatividade concreta do próprio objeto criticado, e essa circunstância se tornaria problemática no capitalismo tardio (Habermas, 2014a, 2014b; Repa, 2017). Como a consciência burguesa teria se mostrado cínica, e ainda mais em tempos de recessão econômica, o recurso à imanência da normatividade é bloqueado. Uma linha de raciocínio semelhante se aplicaria a novos tipos de ideologia, como a consciência tecnocrática ou a consciência fragmentada determinada pelas intervenções sistêmicas livres de normas no mundo da vida. 
O leve ajuste do método: reconstrução normativa e experimentalismo socialista ...

Assim, seria necessário buscar novas estruturas normativas no interior dos procedimentos comunicativos mais ou menos institucionalizados ao longo do processo de modernização. Em vez da consciência burguesa, seria crucial considerar as práticas de entendimento linguístico pertencentes ao mundo da vida modernizado, cujas "estruturas profundas" deixam marcas no "saber intuitivo, pré-teórico" dos atores sociais. $\mathrm{O}$ fato de que as sociedades capitalistas não dispõem de outro recurso criador de legitimação do que os processos democráticos, e estes têm de um modo ou de outro que remeter à esfera pública, mesmo que midiaticamente constituída, tornase o ponto chave do diagnóstico habermasiano que sugere uma ampliação do sentido de imanência. Habermas substitui assim a crítica imanente da ideologia desenvolvida por Marx e por ele mesmo por um modelo de reconstrução racional. Desse modo, a imanência dos potenciais emancipatórios perderia a concretude das formas de consciência e se espalharia por vários núcleos da sociedade. Com razão, Titus Stahl vê no pensamento de Habermas uma espécie de "crítica imanente reconstrutiva" que não trata da autocompreensão dos atores sociais, mas de suas práticas sociais mediadas pela linguagem (Stahl, 2013).

No entanto, as mudanças produzidas por Habermas dividiram a Teoria Crítica subsequente em duas abordagens nem sempre organicamente integradas, embora o próprio Habermas sempre tivesse mantido a pretensão de unidade entre elas: uma atitude suscita preocupações sobre o fundamento normativo dos próprios critérios, enquanto outra tenta entender como esses critérios podem ser efetivos na realidade sociologicamente apreensível. ${ }^{5}$ Por um tempo, as preocupações com a fundação normativa ocuparam o primeiro plano, especialmente após o debate sobre liberalismo e comunitarismo. Seyla Benhabib e Rainer Forst são os teóricos mais representativos nesse contexto. Por outro lado, outras autoras e autores como Rahel Jaeggi e Robin Celikates buscaram resgatar o significado transformador da crítica e da análise social.

O conceito de reconstrução normativa de Honneth visa manter unidas as duas tendências do pós-habermasianismo. Ele é operado para sustentar uma teoria da justiça que cumpra a tarefa de fundamentar os parâmetros normativos da crítica e, ao mesmo tempo, ser uma categoria-chave da análise social que consiga identificar formas de realização desses critérios no sentido de uma crítica imanente às práticas sociais (Honneth, 2002). Através do caminho da reconstrução, o teórico crítico poderia reconhecer os padrões de reconhecimento que fornecem as condições de autorrealização livre e autêntica, distinguir déficits institucionais em comparação com esses padrões normativos, diagnosticar uma ampla gama de fenômenos patológicos e, finalmente, explicar potenciais por novas lutas e transformações.

\footnotetext{
5 Contribuiu decisivamente para essa separação o posfácio de 1973 para Conhecimento e interesse, em que Habermas distingue reconstrução dos fundamentos normativos e a crítica social propriamente dita. As tentativas posteriores de religar as duas tarefas não conseguiram reverter as tendências que partem, positiva ou negativamente, dessa distinção. Cf. Repa, 2017.
} 
Outra característica deve ser adicionada a essa estrutura esquemática dos usos metodológicos da reconstrução. Refiro-me à expressão “reconstrução atualizadora” [aktualisierende Rekonstruktion], que surge em Luta por reconhecimento para designar uma reconstrução da história da teoria com o objetivo sistemático de renovar abordagens específicas, aproveitando as pesquisas empíricas contemporâneas (Honneth, 2013, pp. 118, 180). Nesse sentido, as reconstruções normativas ocorrem geralmente por meio de "reconstruções atualizadoras" da história da teoria e, portanto, têm uma natureza indireta e mediada. Também aqui a inspiração habermasiana é visível:

Reconstrução significa que uma teoria é decomposta e recomposta em uma forma para que possa assim atingir o fim que ela mesma se pôs: esse é um modo normal (quero dizer: normal também para o marxismo) de se relacionar com uma teoria que, sob diversos aspectos, precisa de revisão, mas cujo potencial de estímulo (ainda) não se esgotou (Habermas, 2016, p. 25; cf. Repa, 2012; Nobre, 2013; Deranty, 2011).

De certo modo, Honneth se debruça sobre a história da teoria buscando algo como essa recomposição. Ao mesmo tempo, as teorias assim reconstruídas também operam de maneira reconstrutiva, na medida em que buscam descobrir uma estrutura de reconhecimento subjacente a comportamentos mais ou menos acessíveis empiricamente. A reconstrução atualizadora se volta para teorias que já seriam elas mesmas teorias reconstrutivas. ${ }^{6}$

Apesar dos usos recorrentes da noção de reconstrução nos anos 1990, Honneth passa a aplicar esse conceito de forma mais sistemática apenas no início do século para caracterizar sua própria abordagem. Além disso, ele começa então a considerar toda a teoria crítica como uma série de modelos de crítica reconstrutiva. Em 2001, ao reinterpretar a crítica da ideologia de Marx em termos de reconstrução, ele acaba estendendo esse conceito à Teoria Crítica clássica de tal maneira que "Horkheimer, Adorno e Marcuse sempre buscavam uma via reconstrutiva de fundamentar sua crítica social" e até mesmo as ciências reconstrutivas de Habermas seriam apenas mais alguns exemplos desse caminho (Honneth, 2007, p. 64). As diferenças começariam a surgir apenas pelas formas de justificar os critérios normativos que são entendidos como imanentes à sociedade injusta, alienada e reificada.

Por mais que essa tentativa - no mínimo ousada - de interpretar toda a teoria crítica a partir da ideia de reconstrução seja evidentemente problemática, ela atesta o papel unificador que Honneth procura criar para essa tradição de pensamento. Assim, pode-se dizer que Honneth recupera e remodela a noção de Habermas para evitar a divisão entre as reivindicações de fundamento normativo e crítica social,

6 Isso não é evidente apenas para Hegel, tanto em Jena como na Filosofia do direito (cf. p. ex. Honneth, 2003, p. 73, 2007a, p. 116). De modo geral, as mais diversas contribuições teóricas são vistas por Honneth como uma forma de reconstruir a realidade em função de determinadas estruturas, como valores constitutivos de práticas sociais, formação da identidade, desenvolvimento do direito etc. 
O leve ajuste do método: reconstrução normativa e experimentalismo socialista ...

convertendo metodologicamente a abordagem de Habermas em apenas um momento dessa tradição "reconstrutiva”. Isso explicaria também porque ele se refere tão pouco às abordagens metodológicas de Habermas.

Em grande medida, portanto, o conceito de reconstrução normativa é o elo entre a teoria da justiça ou, de maneira mais ampla, a tarefa de fundamentar normativamente os critérios da crítica, por um lado, e as análises sociais e os diagnósticos históricos por meio dos quais se atestam as possibilidades reais de transformação emancipatória, por outro lado.

É importante observar ainda que, enquanto tal, como reconstrução normativa, essa noção somente ganha corpo em Honneth à medida que ele desenvolve aquele conceito próprio de liberdade que serve de parâmetro de sua teoria da justiça. Não se trata, como em Luta por reconhecimento, das condições intersubjetivas da formação da identidade, ou das autorrelações práticas que as formas de reconhecimento propiciam positivamente na qualidade de autoconfiança (amor), autorrespeito (direito) e estima (solidariedade), cuja negação desencadeia lutas sociais por reconhecimento. Na medida em que Honneth vai se deslocando de uma teoria do conflito para uma teoria da justiça, a ideia de liberdade também vai ocupando o lugar daquele de identidade. ${ }^{7}$

De início, em Sofrimento de indeterminação, o primeiro grande passo em direção a uma teoria da justiça, trata-se ainda de uma "liberdade comunicativa" cujas condições devem ser proporcionadas no interior de uma sociedade a título de fundamentação da autodeterminação. Nesse sentido, a reconstrução atualizadora da filosofia do direito hegeliana se converte em uma

teoria normativa de justiça social que precisa ser fundamentada na forma de uma reconstrução das condições necessárias de autonomia individual, cujas esferas sociais uma sociedade moderna tem que abranger ou dispor para com isso garantir a todos os seus membros a chance de realização de sua autodeterminação (Honneth, 2007a, p. 67).

Tal reconstrução é ao mesmo tempo descritiva e normativa, porque se trata de reconhecer as condições sociais e históricas que permitiram satisfazer as exigências postas com a liberdade comunicativa, e, ao realizar essa tarefa, de desempenhar o papel de um procedimento normativo:

Para poder sublinhar a diferença com o construtivismo de tradição kantiana, talvez

7 Esse movimento começa a se tornar agudo no debate com Nancy Fraser, em que Honneth tenta rechaçar de sua abordagem a valorização da identidade cultural como tal (cf. Honneth, 2003b, p. 191 ss.; sobre o quadro teórico maior do debate e as mudanças que se operam em Honneth a partir dele, cf. Nathalie Bressiani, 2011, 2013). 
o procedimento hegeliano tenha de ser interpretado primeiramente com a ajuda do conceito de "reconstrução normativa": as relações modernas de vida foram reconstruídas de um modo normativo com o fio condutor dos critérios até aqui desenvolvidos, de modo que nestes se revelam aqueles padrões de interação que podem valer como condições imprescindíveis de realização da liberdade individual de todos os membros da sociedade (idem, p. 116).

Dessa maneira, a reconstrução normativa é simultaneamente um conceito de teoria social e de teoria normativa; é um procedimento de método de conhecimento e um procedimento de justificação de normas e desenvolvimentos sociais. Em Sofrimento de indeterminação, o alcance dessa noção ainda se vê determinado pelo fato de que a transição entre a teoria da justiça e a análise social se dá pelo diagnóstico sobre as patologias da liberdade, mais exatamente, das patologias causadas pela indeterminação requerida por concepções negativas e altamente subjetivas de liberdade, cujo preço é a vacuidade e a depressão (cf. também Honneth, 2003b).

Nesse aspecto, a reconstrução normativa ganha o sentido prático inusitado de uma função terapêutica, pois o discernimento das condições sociais da liberdade deve ter um efeito emancipador sobre as concepções abstratas e autonomizadas de liberdade que se enraizaram na modernidade por meio do direito formal e da moral reflexiva.

Ora, o passo filosófico decisivo consiste em atribuir, na forma de diagnóstico, os diversos fenômenos de sofrimento social que no procedimento esboçado deve exercer um papel de causa da enfermidade; aqui, exatamente na passagem para a segunda fase da terapia, encontra-se a conhecida formulação de Wittgenstein sobre a "imagem" que "nos matinha presos" (Honneth, 2007a, p. 100-101).

Não se trataria de uma abordagem subjetiva e individual, uma vez que tais imagens aprisionadoras "se instituem pelas nossas costas como base das atividades de nossa prática cotidiana”, como "formas do espírito objetivo" (idem, p. 101).

Em $O$ direito de liberdade, Honneth desdobra esse enfoque de outra maneira, corrigindo em grande parte os problemas dessa primeira formulação sobre a noção de reconstrução normativa. A teoria das patologias deixa de ser o elo entre a teoria da justiça e a análise social e, consequentemente, reduz-se também a importância de uma terapia voltada para as confusões conceituais envolvidas nas concepções de liberdade individual. ${ }^{8} 0$ interesse se desloca mais para as práticas em que se cristalizam aquelas imagens aprisionadoras. Em grande parte, essa mudança de enfoque é correlata do novo conceito de liberdade. Como dito de início, a liberdade social é remetida a práticas sociais institucionalizadas de reconhecimento, o que obriga a uma visão mais histórica do desenvolvimento das diversas esferas da liberdade. Com isso, as patologias e anomalias diagnosticadas são referidas a desdobramento

8 Para uma reconstituição ampla e detalhada da teoria honnethiana das patologias e anomalias, cf. Teixeira, 2016; sobre o conceito de patologia, cf. Zurn, 2011. 
O leve ajuste do método: reconstrução normativa e experimentalismo socialista ...

sociais historicamente mais palpáveis, sem perder sua importância fundamental para o diagnóstico de época.

$\mathrm{Na}$ obra de 2011, o conceito de reconstrução normativa tem por objetivo descobrir quais práticas e instituições "podem ser consideradas inalienáveis para a reprodução social”, mais precisamente, para "estabilização e implementação" de valores que definem os objetivos da reprodução social (Honneth, 2011, p. 23 [trad., p. 6]). Por outro lado, Honneth insiste em que a reconstrução não deve levar a uma reafirmação pura e simples das práticas existentes, mas à sua correção e transformação, já que a reconstrução é igualmente uma avaliação da sua racionalidade. Nesse aspecto, a reconstrução deve alcançar dois objetivos: mostrar divergências entre práticas e valores essenciais, mas também antecipar “outros caminhos de desenvolvimento que ainda não foram esgotados". Isso significa: "examinar a realidade existente em termos de potenciais de práxis nos quais os valores universais poderiam alcançar uma realização melhor, isto é, mais abrangente ou fiel”. Dessa maneira, a reconstrução normativa detecta na reprodução social aqueles valores fundamentais que contêm "possibilidades objetivas" de transformação institucional em um sentido weberiano, a título de "vias empiricamente controladas de projetar desenvolvimentos sociais” (idem, p. 27 [trad., p. 8]). Em correspondência com isso, exerce-se uma crítica reconstrutiva a respeito do descompasso entre as práticas e as instituições existentes e as possibilidades objetivas dos valores fundamentais aceitos nas sociedades modernas.

O aprofundamento histórico das diversas esferas da liberdade social tornase assim uma exigência do método: é preciso considerar as possibilidades objetivas de desenvolvimento das estruturas fundamentais da liberdade a partir do alcance institucional que uma época histórica permitiu. Daí $O$ direito de liberdade ser a obra de Honneth mais rica em detalhamento histórico, mesmo em comparação com Luta por reconhecimento. Nas três esferas fundamentais, Honneth faz uma reconstrução normativa que vai de par com as realizações historicamente cambiantes das instituições correspondentes, de modo que estas são balizas também para a perspectiva mais normativa.

Ora, como vimos acima, diante de críticas sobre a ausência de uma perspectiva mais radical em relação à transformação da base normativa e institucional da sociedade moderna, Honneth considera que suas reconstruções normativas foram afetadas pela pouca maleabilidade institucional: não se previa em $O$ direito de liberdade a possibilidade de uma "revolução institucional”. Agora, enquanto as estruturas normativas básicas das esferas da liberdade social devem ser mantidas, os arranjos institucionais correspondentes podem se abrir a uma inovação abrangente. Para os nossos propósitos, isso teria de significar que, de algum modo, a reconstrução normativa das esferas sociais da liberdade passaria a colocar em perspectiva as 
possibilidades objetivas do socialismo. Que não se trata disso, porém, se mostra já na proposta de que os tradicionais métodos marxistas de explicação do desenvolvimento histórico têm de ser substituídos por um modelo "experimental", que parece tomar uma distância considerável em relação à investigação reconstrutiva de $O$ direito da liberdade.

O leve ajuste do método que conduz à retomada da ideia do socialismo não é diretamente abordado por Honneth, o que torna duvidoso o grau de sua leveza. É surpreendente que ele não desenrole uma reflexão mais detida sobre o método da reconstrução normativa, dado que foi justamente este o ponto crucial das críticas que the foram dirigidas. ${ }^{9}$

Em parte, esse vazio pode ser explicado pelo fato de que Honneth diagnostica a debilidade do projeto socialista por razões sobretudo normativas. Embora os primeiros socialistas tivessem colocado a liberdade social no centro de sua crítica ao ideário burguês, eles reduziram a envergadura dessa ideia do socialismo ao fazer derivar dos mecanismos econômicos soluções para todas as esferas da liberdade. Com isso, o socialismo cria barreiras internas tanto no sentido da teoria da história quanto na teoria normativa em si mesma. Neste último aspecto, como vimos de início, o conceito de liberdade social permite a Honneth estender o socialismo democrático a questões não intrinsecamente econômicas, de modo que problemas de socialização no âmbito da intimidade também se tornam questões do socialismo, assim como as barreiras de comunicação na esfera pública política.

Por outro lado, quanto à teoria da história, Honneth propõe que os movimentos socialistas assumam a forma de experimentalismo aberto e multifacetado, que substituiria a explicação do desenvolvimento histórico proposto pelo marxismo clássico (Honneth 2017, p. 85 ss. [trad., p. 51 ss.]). A certeza dos movimentos históricos que tanto marcaram as expectativas políticas ao longo do século XIX é substituída por um "arquivo interno de todas as tentativas de uma socialização da esfera econômica a fim de conter uma espécie de 'esteio da memória' para experiências que já foram feitas antes com as vantagens e desvantagens das medidas respectivas (idem, p. 112 [trad., p. 70]). 0 propósito de Honneth nesse aspecto é afastar a ideia de um desenvolvimento inelutável fundado no industrialismo do século XIX. Em vez de leis de desenvolvimento histórico, é preciso antes contar com as diversas experiências feitas ao longo da modernização, de modo que se revele a necessidade daquela comunidade de solidariedade em que se baseia a liberdade social.

9 Sem esquecer aquelas, bastante relevantes, sobre a abstração da história dos movimentos socialistas em toda a sua amplitude. 
O leve ajuste do método: reconstrução normativa e experimentalismo socialista ...

Juntamente com isso, ocorre uma considerável modificação na abordagem do sistema de ação econômico, tal como ele aparecia em $O$ direito da liberdade. Ali, Honneth não diferenciava o mercado e sua forma capitalista, de modo que as anomalias sociais detectadas neste âmbito poderiam ser corrigidas a partir promessas morais do próprio mercado (2011, p. 356 [trad., p. 196]). Assim, podia-se atribuir a esta obra a linha de um "capitalismo reformado", como Eleonora Piromalli o descreve (Piromalli, 2017, p. 4). Em A ideia do socialismo, por sua vez, Honneth pressupõe uma clara diferença entre mercado e capitalismo, o que the permite lançar três configurações não capitalistas do campo econômico: socialismo de mercado, socialismo da sociedade civil (associação de produtores livres que democraticamente geram suas relações) ou socialismo com base no estado de direito democrático, no qual o Estado teria a tarefa de controlar a economia em favor do bem-estar social. Embora Honneth tenha uma clara preferência pelo modelo socialista de mercado, a ideia do experimentalismo requer abertura para todos os arranjos: "Se todos os três modelos constituem candidaturas igualmente possíveis para a tradução institucional do propósito normativo de realizar a liberdade social no interior da esfera econômica, então não pode haver nenhuma pré-decisão apodítica, dispensada de exame" (Honneth, 2017, p. 95 [trad., p. 58]). Além disso, como liberdade social significa uma conexão interna aprendida entre autonomia, autorrealização e solidariedade, experiências significativas podem surgir em toda parte na vida econômica.

Honneth apoia o experimentalismo socialista na ideia de Dewey segundo a qual o desenvolvimento humano tem a ver antes de tudo com a deslimitação da comunicação, ou seja, com a eliminação das barreiras que se impõem à comunicação livre dos membros da sociedade (cf. Petry, 2018). Essa eliminação de barreiras tem uma forma de experimento, impulsionado por grupos sociais excluídos. Esses experimentos estão sempre sujeitos às falhas, de modo que não perdem nunca seu sentido de ensaio histórico. Nesse aspecto, a ideia de Dewey se assemelha às primeiras tentativas socialistas de criar associações libertárias, mesmo que essas tentativas se devessem também ao fato de uma falta de clareza a respeito do funcionamento do capitalismo.

Dessa maneira, o socialismo é remetido às experiências históricas pelas quais os grupos sociais excluídos da comunicação pública buscam articular suas vozes. Ou seja, o socialismo se volta para a conquista do reconhecimento público de reivindicações, invocando normas já implicitamente aceitas e conseguindo assim eliminar as restrições à comunicação, ou seja, os obstáculos à liberdade social. Portanto, o socialismo tem de receber a forma maior que agrupa as lutas históricas por reconhecimento. Na esfera econômica, isso significa a derrubada dos limites impostos pelo capitalismo à liberdade social, a qual seria representada por diversos mecanismos institucionais de ação cooperativa. 
É nesse sentido que deve ser entendido, de modo geral, o experimentalismo histórico: o socialismo não é filtrado por uma teoria de leis do desenvolvimento, mas por uma atualização constante da liberdade social por meio de lutas e inovações. A força dessas experiências para a modificação da realidade capitalista tem que ser ancorada, por outro lado, na sua conservação por meio daquela espécie de memória coletiva. Com esse arquivo das experiências de socialização, o socialismo se torna uma defesa contínua por outras tantas tentativas de enfrentar o capitalismo, como um defensor de todas as iniciativas de alargar a liberdade social na esfera econômica. Essas iniciativas não são representações de interesses de um grupo determinado, como foi antigamente o caso do operariado industrial. 0 socialismo tem de se abrir a todas as reivindicações na esfera econômica e ser sensível particularmente para as camadas dos trabalhadores que não têm chance de articular seus interesses e necessidades, como o chamado "proletariado de serviços".

Contudo, por mais atrativa que seja essa imagem do socialismo democrático experimental, ela não parece derivar de um leve ajuste metodológico da reconstrução normativa, mas antes de um considerável afastamento de seu sentido anterior. A pretendida "maleabilidade" institucional que o experimentalismo acarreta, a própria ideia de ensaios históricos, e inclusive os três modelos mencionados de transformação da esfera econômica - tudo isso não parece se orientar de fato pela diretriz de buscar as "possibilidades objetivas" empiricamente controláveis. A atratividade normativa do socialismo tem de pagar o preço de uma abstração histórica, uma vez que os ensaios socialistas precisam enfrentar justamente a falta de consolidação institucional, como já sugere a necessidade da ideia (de todo modo instigante) de um arquivo socialista.

O problema que a renovação do socialismo provoca na ordem do método transparece na diferença entre as estruturas normativas e sua incorporação institucional. Por mais que o papel crítico da reconstrução dependa, como vimos, dessa diferença, o nível concreto das instituições constituía o ponto de referência para a descoberta dos valores fundamentais que a sociedade colocava na base de sua reprodução social. Ao perder esse nível, e com eles toda a riqueza de análise sobre as patologias e anomalias sociais que é desenvolvida em $O$ direito de liberdade, a reconstrução normativa corre o risco de se tornar abstratamente normativa, quase normativista. 0 fosso entre as possibilidades da liberdade social e o plano institucional que atesta sua objetividade se amplia.

Isso se torna claro justamente no âmbito econômico em que Honneth situa primeiramente o experimentalismo socialista. Em $O$ direito de liberdade, as anomalias do mercado constituíam as principais referências dos desdobramentos da economia capitalista, sem deixar entrever o que poderia ser um ensaio do socialismo. Já na esfera de consumo, em que o consumidor reconhece a contribuição do produtor e 
O leve ajuste do método: reconstrução normativa e experimentalismo socialista ...

que na história do capitalismo sempre contou com manifestações de revolta contra a lógica capitalista (como cooperativas de consumo), seria possível verificar uma das anomalias mais chamativas da economia atual (Honneth, 2011, p. 367 ss., [trad., p. 202 ss.]). Hoje, de acordo com Honneth, as associações de consumidores que garantem a socialização do consumo estão cada vez mais marginalizadas e enfraquecidas, ao mesmo tempo em que o consumismo se propagou como comportamento que privatiza o consumo, deixando de lado o que ele significa em termos de reconhecimento do trabalho. O consumidor é atomizado nesse contexto. Essa anomalia social induzida pelo mecanismo propriamente capitalista do mercado só encontrou algumas barreiras, a partir dos anos setenta, com o movimento estudantil anticonsumista e o movimento ecológico.

Quanto ao mercado de trabalho propriamente dito, as condições atuais do desmantelamento do estado de bem estar social, nos países capitalistas mais ricos, sufocam ainda mais as condições normativas do trabalho como objeto de reconhecimento. Em parte o próprio Estado de bem-estar ajudou a chegar a esse resultado, uma vez que, ao mesmo tempo em que protegia o assalariado e promovia a autoestima, produziu um efeito de dessocialização entre os trabalhadores, tratandoos como unidades isoladas.

Nesse contexto, os sindicatos, as únicas organizações que podiam configurar uma espécie de contrapoder ao capital organizado, não puderam efetivar uma crítica ao capitalismo a partir dos seus pressupostos e, de todo modo, foram cada vez mais minados (Honneth, 2011, p. 432 ss. [trad., p. 233 ss]). Vai de par com esse desenvolvimento uma segmentação mais acentuada da classe trabalhadora, a ponto de a palavra "proletário" designar o trabalhador não qualificado tanto na esfera da indústria quanto na esfera dos serviços, o que enfraquece as já debilitadas organizações do trabalho. A “desorganização da economia capitalista” (idem, p. 445 [trad. p. 245] $)^{10}$ produz assim uma experiência de desvalorização massiva do trabalho remunerado, a precarização das condições de contrato e o aumento de insegurança estrutural, que por si só representam uma denegação de reconhecimento. Em correlação com isso, as resistências assumem formas individualizadas, em vez de articulações coletivas de interesses (idem, p. 459 [trad., p. 247]). Mais ainda, é até mesmo difícil conferir uma indignação massiva da população, uma vez que os processos de dessocialização tendem a individualizar as experiências negativas de redução de salários, precarização e flexibilização. O significado do mercado se reduz

10 Tal desorganização não deve ser entendida como retirada do Estado; antes, o neoliberalismo implica políticas ativas de intervenção estatal: "O Estado é muito mais ativo do que antes na garantia de condições para mercados não regulamentados: não apenas por certas proteções legais sempre necessárias, mas pela reestruturação de todas as infraestruturas de transações capitalistas, o Estado não desempenha o papel mínimo relativo que o ideólogo do laissez-faire quer que ele desempenhe; ele é muito mais ativo e intervém mais do que nunca" (Honneth, 2019, p. 698; sobre o neoliberalismo em Honneth, cf. Fazio, 2019). 
a ser um lugar para a competência individual em otimizar os benefícios. Impera assim a visão cínica de que cada um é responsável por seu destino no mercado de trabalho (cf. também Honneth, 2014; Honneth, Hartmann, 2010).

Se é assim, a única maneira de combinar esse diagnóstico do capitalismo com o projeto socialista parece ser pelo lado negativo. ${ }^{11}$ Justamente por que não se vê muita saída, o socialismo deve ser retomado. O preço dessa exigência é um aumento de abstração no método da reconstrução normativa, em que as possibilidades objetivas perdem sua referência empírica concreta. Com isso, a unidade entre a referência normativa e a realidade empírica que Honneth buscou resgatar no póshabermasianismo corre o risco de fraturar-se mais uma vez.

\section{Referências}

Bressiani, N. (2011). Redistribuição e reconhecimento - Nancy Fraser entre Jürgen Habermas e Axel Honneth. Caderno CRH, 24(62), 331-352. DOI: https: //doi.org/10.1590/S0103-49792011000200007

Bressiani, N. (2013). "Luta por reconhecimento e diagnóstico das patologias sociais". In: Melo, R. (org.), A teoria crítica de Axel Honneth: Reconhecimento, liberdade e justiça. São Paulo: Saraiva.

Deranty, J-Ph. (2011). "Reflective Critical Theory: A Systematic Reconstruction of Axel Honneth's Social Philosophy”. In: Petherbridge, D. (org.), Axel Honneth: Critical Essays. Leiden: Brill.

Dubiel, H. (1978). Wissenschaftsorganisation und politische Erfahrung. Studien zur frühen Kritischen Theorie. Frankfurt am Main: Suhrkamp.

Fazio, G. (2019). From Hegel to Foucault and back? On Axel Honneth's interpretation of neoliberalism. Philosophy \& Social Criticism, 45(6), 643-654. DOI: https://doi.org/10.1177/0191453719842355

Habermas, J. (1976/1984). “Was heist Universalpragmatik?” In: Vorstudien und Ergänzugen zur Theorie des kommunikativen Handelns. Frankfurt am Main: Suhrkamp.

Habermas, J. (1989). "Ciências Sociais Reconstrutivas versus Ciências Sociais Compreensivas.". In: Consciência moral e agir comunicativo. Trad. Guido A. de Almeida. Rio de Janeiro: Tempo Brasileiro.

Habermas, J. (1990). What Does Socialism Mean Today? New Left Review, I-183, 3-21.

Habermas, J. (1992). Faktizität und Geltung. Beiträge zur Diskurstheorie des Rechts und des demokratischen Rechtsstaats. Frankfurt am Main: Suhrkamp.

Habermas, J. (2013). “Direito natural e revolução”. In: Teoria e práxis. Trad. Rúrion Melo. São Paulo: Editora UNESP.

Habermas, J. (2014a). Conhecimento e interesse. Trad. Luiz Repa. São Paulo: Editora UNESP.

11 Deixo de lado a possibilidade de pensar tendências socialistas oriundas das esferas das relações pessoais (inédita até onde posso ver) e da esfera pública política. 
O leve ajuste do método: reconstrução normativa e experimentalismo socialista ...

Habermas, J. (2014b). “Técnica e ciência como “ideologia””. In: Técnica e ciência como 'ideologia'. Trad. Felipe Gonçalves Silva. São Paulo: Editora UNESP.

Habermas, J. (2016). "Materialismo histórico e desenvolvimento de estruturas normativas". In: Para a reconstrução do materialismo histórico. Trad. Rúrion Melo. São Paulo: Editora UNESP.

Honneth, A. (2002). Grounding recognition: A rejoinder to critical questions. Inquiry: An interdisciplinary. Journal of Philosophy, 45(4), 499-519. DOI: https: //doi.org/10.1080/002017402320947577

Honneth, A. (2003a). Luta por reconhecimento: A gramática moral dos conflitos sociais. Trad. Luiz Repa. São Paulo, Editora 34.

Honneth, A. (2003b). Patologias da liberdade individual: o diagnóstico hegeliano de época e o presente. Novos Estudos Cebrap, 66(2), 77-90.

Honneth, A. (2007a). Sofrimento de indeterminação. Trad. Rúrion Melo. São Paulo: Esfera Pública.

Honneth, A. (2007b). "Reconstruktive Gesellschaftskritik unter genealogischem Vorbehalt". In: Pathologien der Vernunft. Geschichte und Gegenwart der Kritischen Theorie. Frankfurt am Main: Suhrkamp.

Honneth, A. (2011). Das Recht der Freiheit. Frankfurt am Main: Suhrkamp. [Tradução em inglês: Freedom's Right. New York: Columbia University Press, 2014].

Honneth, A. (2014). Reconhecimento como ideologia: sobre o nexo de moral e poder. Trad. Ricardo Crissiuma. fevereiro, 7.

Honneth, A. (2015). Rejoinder. Critical Horizons, 16(2), 204-226. DOI: https: //doi.org/10.1179/1440991715Z.00000000048

Honneth, A. (2017). Die Idee des Sozialismus. Erweiterte Ausgabe. Frankfurt am Main: Suhrkamp. [Tradução em inglês: The Idea of Socialism. Cambridge: Polity Press, 2017].

Honneth, A. (2019). Recognition, democracy and social liberty: A reply. Philosophy \& Social Criticism, 45(6), 694-708. DOI: https: / / doi.org/10.1177/0191453719843439

Honneth, A, Hartmann, M. (2010) "Paradoxien der Kapitlistischen Modernisierung. Ein Untersuchungsprogramm”. In: Honneth, A. Das Ich im Wir. Studien zur Anerkennungstheorie. Frankfurt am Main: Suhrkamp.

Horkheimer, M. (1988). “Traditionelle und kritische Theorie”. In: Gesammelte Schriften. Band 4. Frankfurt am Main: Fischer.

Jütten, T. (2015). Is the market a sphere of social freedom? Critical Horizons, 16(2), 187-203. DOI: https://doi.org/10.1179/1440991715Z.00000000047

Marcuse, H. (1969). An Essay on Liberation. Boston: Beacon.

Nobre, M. (2013) "Reconstrução em dois níveis: Um aspecto do modelo crítico de Axel Honneth’. In: Melo, R. (org.). A teoria crítica de Axel Honneth: Reconhecimento, liberdade e justiça. São Paulo: Saraiva.

Nobre, M. (2015). “How Practical Can Critical Theory Be?”. In: Ludovisi, S. G. (org.). Critical Theory and the Challenge of Praxis. Farnham: Ashgate. 
Petry, F. (2018). Socialismo, liberalismo e educação para a democracia: Honneth e Dewey em discussão. Civitas - Revista De Ciências Sociais, 18(3), 611-629. DOI: https: //doi.org/10.15448/1984-7289.2018.3.30023

Piromalli, E. (2017). Does socialism need fraternity? On Axel Honneth's The Idea of Socialism. European Journal of Political Theory, 19(3), 375-395. DOI: https: //doi.org/10.1177/1474885117718431

Pollock, F. (2019). "A situação atual do capitalismo e as perspectivas de uma nova ordem de planificação econômica (1932)”. In: Fleck, A., Caux, L. Ph. (orgs.). Crise e transformação estrutural do capitalismo: artigos na Revista do Instituto de Pesquisa Social, 1932-1941. Florianópolis: Nefipo.

Repa, L. (2012). “A reconstrução da história da teoria: observações sobre um procedimento da Teoria da ação comunicativa”. In: Repa, L., Nobre, M. (orgs.). Habermas e a reconstrução. Campinas: Papirus.

Repa, L. (2017). Compreensões de reconstrução: sobre a noção de crítica reconstrutiva em Habermas e Celikates. Trans/Form/Ação, 40(3), 9-28. DOI: https: //doi.org/10.1590/s0101-31732017000300002

Repa, L., Nobre, M. (2012). "Reconstruindo Habermas: Etapas e sentido de um percurso. In: Repa, L., Nobre, M. (orgs.). Habermas e a reconstrução. Campinas: Papirus.

Schaub, J. (2015). Misdevelopments, Pathologies, and Normative Revolutions: Normative Reconstruction as Method of Critical Theory. Critical Horizons, 16(2), 107-130.

Silva, F. G. (2013). “Um ponto cego no pensamento político? Teoria Crítica e a democratização da intimidade". In: Melo, R. (org.). A teoria crítica de Axel Honneth: Reconhecimento, liberdade e justiça. São Paulo: Saraiva.

Stahl, T. (2013). Habermas and the Project of Immanent Critique. Constellations, 20(4), 533-552. DOI: https://doi.org/10.1111/1467-8675.12057

Teixeira, M. (2016). Patologias sociais, sofrimento e resistência: Reconstrução da negatividade latente na teoria crítica de Axel Honneth. Tese de doutorado, Campinas: Unicamp.

Terra, R. (2011). “Os limites do paradigma da revolução: ciência, técnica e movimentos sociais". In: Nobre, M. (org.). Curso livre de Teoria Crítica. Campinas: Papirus.

Zurn, Chr. (2011). "Social Pathologies as Second-Order Disorders". In: Petherbridge, D. (org.), Axel Honneth: Critical Essays. Leiden: Brill.

Esta obra está licenciada com uma Licença Creative Commons Atribuição-NãoComercial-

-Compartilhalgual 4.0 Internacional.

https://creativecommons.org/licenses/by-nc-sa/4.0/

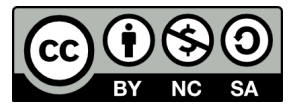

